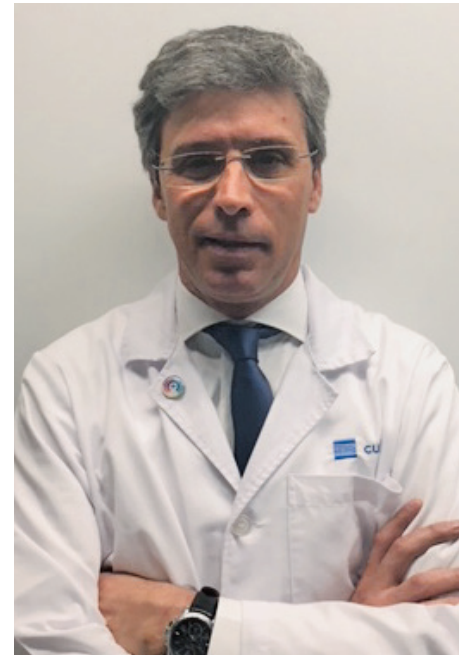

\title{
A Ortopedia do Futuro
}

\section{The Orthopaedics of the Future}

\author{
Eduardo Mendes
}

É com enorme prazer que participo neste número da Gazeta Médica, a revista científica da José de Mello Saúde, com a redação do seu editorial. Sendo já de todos nós conhecida a excelência do seu conteúdo científico, coroada com a sua indexação no Directory of Open Access Journals (DOAJ), mais uma vez integra um conjunto de artigos originais de investigação, reflexão e revisão de diversas áreas do conhecimento médico.

A constituição de corpos clínicos diferenciados é a génese do sucesso do Grupo José de Mello Saúde, em todas as suas Unidades. Pretende-se, desta forma, corresponder aos anseios dos doentes, que querem ser tratados pelos "melhores médicos". Para tal, consideramos a subespecialização como a única possibilidade de chegar à excelência, quer pela concentração do conteúdo científico, quer pela experiência acumulada. Este número pretende dar uma perspetiva do futuro de áreas de conhecimento médico, como a Imagiologia do século XXI e a utilização de novas tecnologias em crianças e jovens, resultante da evolução digital e eletrónica ao serviço da clínica. Esta edição apresenta, também, diversos casos clínicos, resultado da atividade desenvolvida nas diversas Unidades.

Por deformação profissional, de especialidade, vou focar-me na evolução da ortopedia como especialidade médica, eminentemente cirúrgica, de "trato fino e delicado". O adágio: "grande incisão, grande cirurgião" associado à especificidade da cirurgia ortopédica em termos de técnicas e materiais, foi em tempos idos imagem desta especialidade.

A compreensão do papel da Ortopedia nos nossos dias implica conhecimento do passado, da sua génese.

A Ortopedia é o ramo médico que tem como objeto o aparelho locomotor. O termo foi pela primeira vez utilizado por Nicolas Andry, Professor da Universidade de Paris, em 1741, significando a correção das deformidades musculoesqueléticas nas crianças. A ortopedia moderna foi iniciada com os trabalhos de Hugh Owen Thomas e Robert Jones, que recomendavam o repouso como o melhor tratamento para as fraturas do fémur e da tuberculose óssea.

Mas foi com as duas Grandes Guerras do século XX que se iniciaram os progressos no tratamento do trauma. As amputações predominavam como forma de tratamento das fraturas na Primeira Guerra Mundial, mas os primeiros encavilhamentos intramedulares do fémur e tíbia de Gerhard Kuntsher revolucionaram a sua abordagem.

Contudo, a grande escola de Trauma nasceu em 1958, em Davos, Suíça, fundada por Muller, Schneider, Willenegger e Allgower (escola AO: Arbeitsgemeinschaft fur Osteosynthesefragen - Associação para o estudo da fixação interna), que ainda hoje mantém os princípios atuais que orientam toda a formação em traumatologia. A evolução resulta da investigação em ciência básica, centrando a biologia no processo da cura óssea.

O tratamento moderno da artrose da anca iniciou-se com Sir John Charnley, em 1960, sendo o princípio daquela que é a cirurgia mais realizada em todo o mundo! 
Nos últimos 40 anos o progresso tecnológico foi vertiginoso.

Masake Watanabe e Bob Jackson introduziram a cirurgia artroscópica no mundo ortopédico, nos anos sessenta, revolucionando completamente a medicina desportiva.

Hoje a alta competição desportiva tem ao seu dispor técnicas de abordagem articular com portas de entrada e agressividade cirúrgica minor, terapêuticas conservadoras e tempos de recuperação curtos.

Um problema sério do atual mundo ocidental resulta da melhoria dos cuidados médicos, com o consequente aumento da esperança de vida. Hoje vive-se muito mais, em média mais 10 a 15 anos que há um século atrás. Este envelhecimento populacional implica custos elevados em termos de cuidados médicos em geral e ortopédicos em particular.

A osteoporose afeta mais de 200 milhões de pessoas nos Estados Unidos e União Europeia, sendo a primeira fratura o principal fator de risco para uma nova fratura. Fratura do fémur proximal, coluna, rádio distal são as mais frequentes, congestionando diariamente os serviços de ortopedia e implicando custos económicos elevados diretos.

A abordagem cirúrgica da fratura osteoporótica é hoje em dia um desafio técnico em termos de cirurgia e implantes utilizados. Os princípios, apesar de manterem a base, têm a particularidade e o desafio da fixação mecânica de osso frágil, utilizando implantes longos de fixação bloqueada e de preservação biológica. É esta preservação biológica que está no princípio MIS (minimaly invasive surgery) realizando a mesma técnica, mas com abordagens mínimas utilizando suportes de imagem, (C-ARM O-ARM) ou amplificação ótica (lupas ou microscópio).

Executar cirurgia de coluna, por técnicas minimamente invasivas, corresponde a um avanço enorme na redução da agressividade cirúrgica. Torna-se ainda mais significativo no tratamento cirúrgico da escoliose pela redução da abordagem, do tempo cirúrgico, e das perdas hemáticas, resultando habitualmente em tempos de internamento e de recuperação mais rápidos.

Encerro o editorial assinalando a evolução tecnológica vertiginosa ao dispor da medicina/cirurgia recordando, todavia, que a nossa atividade clínica nunca pode deixar de considerar o doente como o motivo de toda a dedicação. 